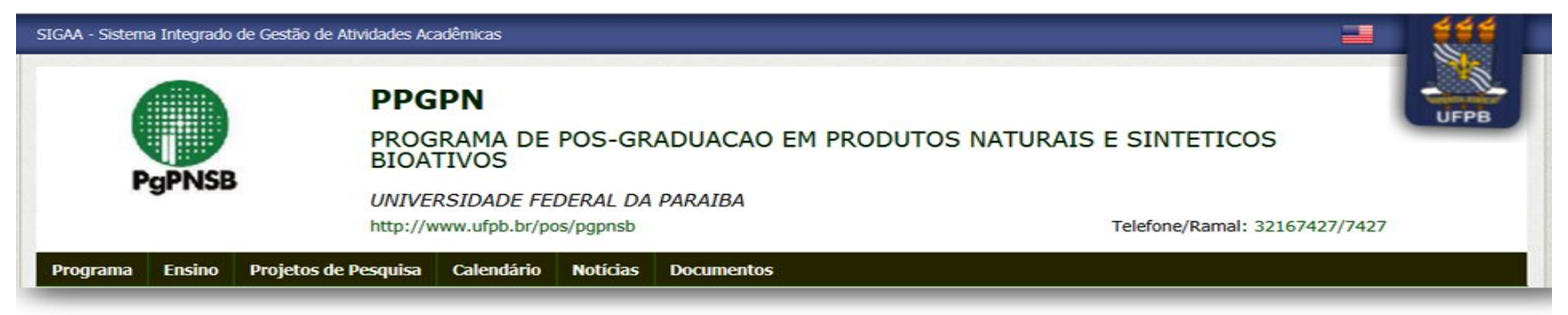

\title{
SciForum
}

MOL2NET

\section{The Anti-Inflammatory Effects of the Zingiber officinale Roscoe}

\author{
Lucas Miguel Lima do Amaral ${ }^{1, *}$, Raiza Santos de Góis ${ }^{2}$, Cláudia Kowalesky Silva ${ }^{3}$,Natalia Diniz \\ Nunes Pazos ${ }^{4}$, Paulo Rogério Ferreti Bonan ${ }^{5}$, Lucio Roberto Cançado Castellano ${ }^{6}$, Daniela \\ Bomfim de Barros ${ }^{7}$ and Vanessa de Melo Cavalcanti Dantas \\ 1 Faculdade Internacional da Paraíba; E-mail: amaralmiguel736@gmail.com; Tel.:+55 83986560874 \\ 2 Faculdade Internacional da Paraíba; E-mail: raizagois@ @otmail.com \\ $3 \quad$ Faculdade Internacional da Paraíba; E-mail: claudiakowalesky@ hotmail.com \\ 4 Faculdade Maurício de Nassau; E-mail: natalia_dnpazos@hotmail.com \\ 5 Universidade Federal da Paraíba; E-mail: pbonan@ yahoo.com \\ 6 Universidade Federal da Paraíba; E-mail: luciocastellano@ccs.ufpb.br \\ 7 Faculdade Internacional da Paraíba; E-mail: danielabbarros@ outlook.com \\ $8 \quad$ Faculdade Internacional da Paraíba; E-mail: vanessadantas.prof@gmail.com \\ Received: / Accepted: / Published:
}

\begin{abstract}
Introduction: The inflammatory process is one of the main means of protection of innate immunity, and this response only occurs when there is some injury, being of physical, chemical and biological causes. Inflammation has as main signals vasodilation, increases the permeability of the capillaries, allowing fluid to flow into the interstitial space, coagulation of the fluid in the interstitial space by the presence of large amounts of coagulation proteins, migration of leukocytes to tissues, and end products, their end products histamine, serotonin, prostaglandins and bradykinin. Zingiber officinale Roscoe popularly known as ginger, has been widely used in traditional medicine for the treatment of various diseases such as muscle aches, fever, sore throats, indigestion and vomiting. The objective of this work was to address the anti-inflammatory effects of the Zingiber officinale Roscoe plant. Methodology: Given the above, the present work is a review that aims to report articles that address the anti-inflammatory effects of the plant Zingiber officinale Roscoe, using bibliographic data. Results and Discussion: Anti-inflammatory drugs have the function of preventing this cascade of reactions, being steroidal anti-inflammatory drugs (AIEs), phospholipase A2 inhibitors and nonsteroidal anti-inflammatory drugs (NSAIDs), cyclooxygenase inhibitors -1 and COX-2). Because these drugs have a number of adverse effects, some studies have shown the anti-inflammatory effect of Zingiber officinale Roscoe, popularly known as Ginger, where its main components, gingerols and shogaols, can inhibit the synthesis of several proinflammatory cytokines (IL-1, TNF- $\alpha$ and IL-6), chemokines, and inhibited the action of prostaglandins and the enzyme cyclooxygenase-2 (COX-2). In addition, ginger components have been shown to be more effective than conventional non-steroidal anti-inflammatory drugs (NSAIDs), with fewer side effects. Conclusion: Through the results obtained it has been demonstrated that Zingiber officinale Roscoe possesses a high anti- inflammatory.
\end{abstract}


Keywords:Zingiberofficinale Roscoe; Immunology; Anti-inflammatory

Mol2Net YouTube channel: http://bit.do/mol2net-tube

YouTube link: please,paste here the link to your personal YouTube video, if any.

\section{Introduction}

In an inflammatory process it is possible to observe loss of homeostasis, with several marked features in the inflamed tissue. The drugs used in this process are anti-inflammatories represented by glucocorticoids and nonsteroidal antiinflammatory drugs (NSAIDs), which act to inhibit the transcription of the cyclooxygenase-2 (COX-2) enzyme gene and induce the protein In addition, lipocortin, a phospholipase A2 inhibitor, reduces the production of proinflammatory cytokines, such as TNF- $\alpha$ and IL-1 (MAHLUJI et al., 2013; VIEIRA et al., 2014; KULMAKARNI et al., 2016). However, prolonged use of these drugs causes several side effects, which impairs the quality of life of patients and favors the appearance of ulcers, renal failure and hemorrhages (HABIB et al., 2008).

This plant has been applied in several pathologies including myalgias, muscle pain, fever, sore throat, indigestion, vomiting and inflammatory conditions such as osteoarthritis, migraines, hyperlipidemia, hyperglycemia and neoplasias (Lee et al., 2012; LEE et al., 2012 ). Thus, the objective of this study is to highlight the anti-inflammatory effects provided by the Zingiber offinacele Roscoe through a bibliographic review.

\section{Results and Discussion}

Gingerols and shogaols, components present in this plant, act to inhibit the synthesis of several pro-inflammatory agents including the cytokines IL-1, TNF-a, IL-6 and IL-8, along with the inhibition of prostaglandins (PG) and enzymes of leukotriene (LT) synthesis (LI et al., 2012, JUSTO et al., 2015). Ginger has the potential to regulate the activation of $\mathrm{NF}-\mathrm{kB}$, inhibition of the synthesis of reactive oxygen species (ROS), $\mathrm{NO}$ and induction of cellular apoptosis in neoplastic cells (LEE at al., 2012; MAHLUJI et al. In addition,
In a study performed with mice showing neoplasias in the liver, a high expression of TNF$\alpha$ cytokines was demonstrated, which was interrupted when supplemented with ginger extract (HABIB et al., 2008; VIEIRA et al., 2014). The decrease in the concentration of cytokines evidenced in the inflammatory processes, which occurs after supplementation with the extract of Zingiber officinale Roscoe, can be correlated through the capacity of regulation in the levels of NF-Kb, with consequent decrease of IL-6 and TNF-a and inhibition of COX-2 enzyme production (HABIB et al., 2008; MAHLUJI et al., 2013; ARABLOU et al., 2014).

Corroborating, a research carried out with female mice of the lewis line, that turned out acute and chronic arthritis, were treated with essential oil derived from ginger, and the antiinflammatory effects of ginger extracts were demonstrated, suggesting that the efficacy is due to the additive effects of both classes of metabolites present in the crude extract (FUNK et al., 2016).

\section{Materials and Methods}

The present work was carried out through a bibliographic review, involving data collected between 2008 and 2016, using SciELO (Scientific Electonic Library Online), Medline (Medical Literature Analysis and Retrieval System Online), Latin American and Caribbean Literature in Health Sciences (Lilacs) and PUBMED. The criteria used to select the articles were: those published in English and Portuguese, with the following descriptors: "Zingiber Officinale Roscoe", "Anti-inflammatory", "Inflammation" and "Immune System". 


\section{Conclusions}

Zinguber officinale Roscoe presents an excellent anti-inflammatory potential, by the ability to suppress diverse cellular responses and cytokines involved throughout the inflammatory process. However, further studies should be performed with the components of Zingiber officinale Roscoe to reduce the risks of toxicity and reactions in patients who use it.

\section{Acknowledgments}

I thank Professor Vanessa Dantas for her guidance and the LACEC research group for all scientific support given during my academic experience and construction of this work.

\section{Conflicts of Interest}

The author states that there is no conflict of interest.

\section{References}

1. Arablou,T.; Aryaeian, N.The effect of ginger consumption on glycemic status, lipid profile and some inflammatory markers in patients whith type 2 diabetes mellitus. Intern Journ of Food Scienc and Nutrit, 2014, https://doi.org/10.3109/09637486.2014.880671.Available online: https://www.tandfonline.com/doi/full/10.3109/09637486.2014.880671 (accessed on 01sept2018).

2. Funk, J.; Frye, J. Anti-inflammatory of the essential oils of ginger (Zingiber officinale Roscoe) in experimental rheumatoid arthritis. Sience Direct, 2016, https://doi.org/10.1016/j.phanu.2016.02.004. Available online: https://www.sciencedirect.com/science/article/pii/S2213434416300056 (accessed on 01sept 2018).

3. Habib.S.; Makpol, S. Ginger extrat (Zingiber officinale) has anti-cancer and anti-inflammatory effects on ethionine-induced hepatoma rats.SciELO, 2008, http://dx.doi.org/10.1590/S180759322008000600017. Available online: ww.scielo.br/scielo.php?script=sci_arttext\&pid=S1807-59322008000600017. (Accessed on 01sept2018).

4. Justo.O.; Simoni, P. Evaluation of in vitro anti-inflammatory effects of crude ginger an rosemary extracts obtained through supercritical $\mathrm{CO}_{2}$ extraction on macrophage and tumor cell line: the influence of vehicle type. BMC Part of Springer Nature,2015, https://doi.org/10.1186/s12906-015-0896-9.Available online: https://bmccomplementalternmed.biomedcentral.com/articles/10.1186/s12906-015-0896-9. (accessed on 01sept2018).

5. Lee. H.; Park, S .1-dehydro-[10]-gingerdione from ginger inhibits IKK $\beta$ activity for NF-kB activation and suppresses NF-kB-regulated expression of inflammatory genes. British Pharmacological Society, 2012, https://doi.org/10.1111/j.1476-5381.2012.01980.x. Available online: https://bpspubs.onlinelibrary.wiley.com/doi/abs/10.1111/j.1476-5381.2012.01980.x. (accessed on 01sept2018).

6. Li. X.;MacGrath,K. Attenuation of liver pro-inflammatory responses by Zingiber officinale via inhibition of NF-kappa B activation in high-fat diet-fed rats. Wiley Online Library, 2011, https://doi.org/10.1111/j.1742-7843.2011.00791.x. Availeble online: https://onlinelibrary.wiley.com/doi/abs/10.1111/j.1742-7843.2011.00791.x. (acessed on 01sept2018).

7. NCBI/PMC Available online: https://www.ncbi.nlm.nih.gov/pmc/articles/PMC3848205/. (accessed on 01sept 2018).

8. Vieira, N.; Tomioto,F.Anti-inflammatory effect of ginger and possible signaling pathway. Semina: Ciências Biológicas e da Saúde, 2014, http://dx.doi.org/10.5433/1679-

0367.2014v35n1p149.

Available online:http://www.uel.br/revistas/uel/index.php/seminabio/article/view/17125. ． (accessedon 01sept2018). 